\title{
Respiratory deposition of atmospheric aerosols
}

\author{
N. A. Kgabi \\ Department of Physics, North-West University, Mmabatho, South Africa
}

\begin{abstract}
While filtration occurs in a fixed system at a steady flow rate, respiratory deposition occurs in a system of changing geometry, with a flow that changes with time and cycles in direction. An understanding of how and where particles deposit in our lungs is necessary in order to evaluate properly the toxicity of aerosols. In this study the effect of particle size, wind speed and direction on respiratory deposition was investigated. The inhalable fraction (IF), which gives an indication of the efficiency of particle entry into the nose or mouth, as well as the total deposition fraction (DF) in the respiratory system, showed an increase as particle diameter decreased. Both the IF and DF showed an increase as ambient air velocity increased above $4 \mathrm{~m} . \mathrm{s}-1$ for particles with aerodynamic diameters 10, 2.5, 1.0 and $0.4 \mu \mathrm{m}$. A reasonable correlation between mass concentrations and wind speed was obtained for all the sizes investigated.
\end{abstract}

Keywords: inhalability, respiratory deposition, particle size, wind speed.

\section{Introduction}

Exposure to ambient particulate matter has been associated with a range of adverse health effects; including: premature mortality, aggravation of existing respiratory conditions, changes to lung tissues and structures, and altered respiratory defence mechanisms.

For healthy adults, during inhalation, the incoming air negotiates a series of direction changes as it flows from nose (mouth) to the alveolar region. The respiratory system can be divided into three main regions namely the head airways, tracheobronchial region, and the alveolar deposition. According to Hinds [1], regional deposition is important for assessing the potential hazard inhaled particles. 
The entry of particles into the mouth or nose can be thought of as a sampling process that includes isokinetic and still-air sampling; however, the human head is a blunt sampler with a complex geometry [2].

The entry of aerosols into the mouth or nose is affected by the human head, which distorts the airflow approaching the mouth or nose (i.e. inhalability). The efficiency of particle entry into the nose or mouth can be characterized by the aspiration efficiency, inhalability, or inhalable fraction $(I F)$, and the fraction of particles originally in the volume of air inhaled. The inhalable fraction, which is usually less than one, depends on particle aerodynamic diameter and the external wind velocity and direction.

Meteorological observations are critical for analysing and predicting atmospheric dispersion and respiratory deposition of gases and particles. Depending upon which dispersion variables (e.g. transport, diffusion, stability, deposition, plume rise) are important for a particular problem, a corresponding suite of meteorological parameters must be quantified through observation, modelling or a combination of both. These parameters can include wind speed and direction, temperature, humidity, precipitation type and intensity, mixing height, turbulence, and energy fluxes [3]. For respiratory deposition however, wind speed and direction are very important. The diffusion of atmospheric pollutants into a greater volume of atmosphere reduces the concentration of a polluting material. This occurs most effectively under unstable conditions of free convection when the mixing layer is deep, which occurs frequently throughout Southern Africa, in summer during the day [4].

Wind direction determines the path followed by pollutants. Although the mean wind speed may remain approximately unchanged over a period of time, short period direction and speed changes due to turbulence cause the plume to diffuse sideways [4].

\section{Experimental methods}

The PM concentrations discussed in this study was obtained from 'mines' study site Rustenburg situated between longitude 250 33' 10.9" south and latitude 270 13 ' 28.6" east at the accuracy of 4 meters, and characterized by the platinum mining industry. Figure 1 shows the actual location of the study site.

The sampling procedure involved pre-treatment (greasing) and weighing of filters, as well as the actual sampling of particles. The polycarbonate foils were placed onto the collection plates and fastened with a stainless steel holder ring while ensuring that there were no bubbles underneath the foil, and that no wrinkles appeared before the foils were greased. That was achieved, by leaving a margin of approx 2-3 $\mathrm{mm}$ between the holder ring and the greased area of the foil.

The instrument used for weighing the filters is a Sartorius Analytic A 2005 electronic analytical balance. The actual sampling of PM involved assembling and disassembling of cascade impactor. First the filter was placed down the rough side up, on the stainless steel screen. Then, the large base plate was placed down over the filter paper. The rubber gasket $(\mathrm{P} / \mathrm{N}$ TE-5018) on the bottom of 


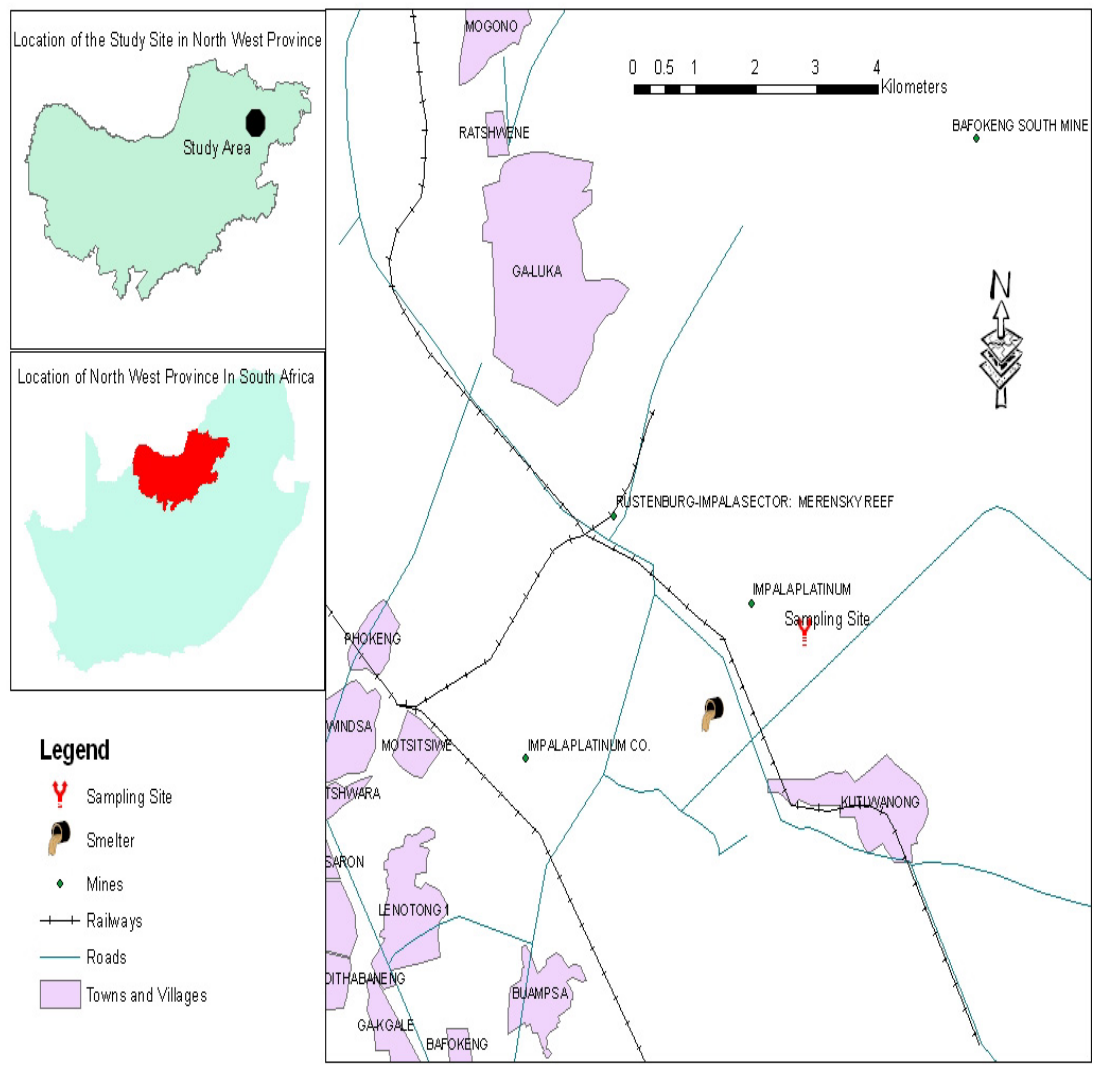

Figure 1: $\quad$ Location of the 'mines' study site in Rustenburg.

the base plate fits around the periphery of the filter in a manner identical to the existing filter holder frame. A collection substrate was placed down on the base plate. Then, subsequent Impactor metal stages were place down over the two treaded studs, starting first with the highest number stage.

During each measurement one backup (Teflon) filter and three greased polycarbonate foils were used. Preferably the assembling of the impactor takes place in a laminar flow chamber free of particulate pollution.

The South African Weather Services (SAWS) determined the meteorological data used in this study.

The inhalability data was computed in terms of the inhalable fraction $I F$ $\left(d_{a}\right)$, which is given by:

$$
I F\left(d_{a}\right)=0.5\left(1+\exp \left(-0.06 d_{a}\right)\right) \text { for } U_{o}<4 \mathrm{~m} / \mathrm{s}
$$


where $d_{a}$ is the aerodynamic diameter in $\mu \mathrm{m}$. For ambient air velocity $U_{o}$ greater than $4 \mathrm{~m} / \mathrm{s}$, IF is given by Vincent et al. [5]:

$$
\operatorname{IF}\left(d_{a}, U_{o}\right)=0.5\left(1+\exp \left(-0.06 d_{a}\right)\right)+10^{-5} U_{o}^{2.75} \exp \left(0.055 d_{a}\right)
$$

Nasal inhalability $I F_{N}$ can be approximated according to Hinds et al. [6] as:

$$
I F_{N}\left(d_{a}\right)=0.035+0.965 \exp \left(-0.000113 d_{a}^{2.74}\right)
$$

The total deposition fraction (DF), which is the sum of the regional depositions in the respiratory system, is given according to the International Commission on Radiological Protection (ICRP) model by

$$
D F=I F\left(0.0587+\frac{0.911}{1+\exp \left(4.77+1.485 \ln d_{p}\right.}+\frac{0.943}{1+\exp \left(0.503+2.5 \ln d_{p}\right.}\right)
$$

where $d_{p}$ is particle size in $\mu \mathrm{m}$, and IF is the inhalable fraction. The equations for deposition fraction for the head airways, tracheobronchial, and alveolar regions are given in Hinds [1].

\section{Discussion of results}

\subsection{Deposition and particle size}

The inhalable fractions (IF) for PM10, PM2.5, PM1.0 and PM $<1$ obtained for this study ranged between 0.999 and 1.000. The relationship between particle size and inhalability and deposition is given in Table 1.

Table 1: $\quad$ Deposition and inhalable fractions for large particle diameters.

\begin{tabular}{|c|c|c|}
\hline Diameter (D) & Inhalable Fraction (IF) & Deposition Fraction (DF) \\
\hline 10.0 & 0.9999997 & 1.9126954 \\
\hline 2.5 & 0.9999999 & 1.9126993 \\
\hline 1.0 & 1.0000000 & 1.9126998 \\
\hline 0.4 & 1.0000000 & 1.9126999 \\
\hline Mean & $\mathbf{1 . 0}$ & $\mathbf{1 . 9}$ \\
\hline $\begin{array}{c}\text { Standard } \\
\text { Deviation }\end{array}$ & $\mathbf{1 . 4 \times 1 0 ^ { - 7 }}$ & $\mathbf{2 . 1 \times 1 0 ^ { - 6 }}$ \\
\hline
\end{tabular}


Polynomial regression for the data in Table 1 showed that particle size and respiratory deposition are highly correlated with $\mathrm{R}^{2}=0.99$. The polynomial regression showed a y-intercept of 1.91 with a gradient of -0.48 , which shows an increase in respiratory deposition as particle size is decreased.

The particle size and inhalability were also found to be highly correlated with $\mathrm{R}^{2}$ of 0.975 . The polynomial regression showed a $\mathrm{y}$-intercept of 1 with a gradient of $-0,03$, which also shows an increase in inhalability as particle size becomes small. The relationships are given in Table 1 . The relations obtained highlight the importance of determining the effect of wind speed and other meteorological parameters on particle size and concentration.

\subsection{PM concentrations and meteorology}

Meteorology and PM concentrations determine the efficiency of entry and settling of particles in the respiratory system. Wind speed is crucial in determining the inhalability and deposition of particles since it governs movement and deposition. Table 2 gives the concentrations of varied sizes of particulates and the wind speed.

The wind speed shows an increase as PM concentration decreases. This could be expected since, according to Chow [7], the low wind speed and temperature in winter favours the accumulation of pollutants, while the high temperature in summer favours air convection and the dispersion of pollutants. In addition, the barer surface in winter would re-suspend more dust while more wet precipitation in summer would wash out more particles. The fact that most parts of the country experiences dry winters may also account for the high levels of particulate matter, since re-suspension of dust is favoured.

Table 2: $\quad$ Wind speed, day-time and night-time PM concentrations.

\begin{tabular}{|c|c|c|c|c|c|}
\hline \multirow{2}{*}{ DATE } & \multicolumn{4}{|c|}{ DAY-TIME CONCENTATION } & \multirow{2}{*}{$\begin{array}{c}\text { DAY-TIME } \\
\text { WIND SPEED }\end{array}$} \\
\cline { 2 - 5 } & PM10 & PM2.5 & PM1.0 & PM $<1$ & 1.12 \\
\hline 20 JUN 06 & 3.51 & 3.08 & 3.41 & 4.09 & 1.25 \\
\hline 21 JUN 06 & 3.08 & 2.78 & 2.68 & 3.45 & 1.38 \\
\hline 22 JUN 06 & 3.24 & 3.08 & 2.55 & 3.60 & 1.0 \\
\hline 23 JUN 06 & 2.74 & 1.59 & 2.73 & 3.46 & 0.95 \\
\hline 24 JUN 06 & 2.86 & 2.53 & 1.75 & 3.68 & 0.88 \\
\hline 25 JUN 06 & 2.99 & 2.89 & 2.95 & 3.68 & \multirow{2}{*}{ NIGHT-TIME } \\
\hline DATE & & NIGHT-TIME CONCENTATION & WIND SPEED \\
\cline { 2 - 5 } & PM10 & PM2.5 & PM1.0 & PM $<1$ & 1.08 \\
\hline 20 JUN 06 & 0.09 & 0.22 & 0.21 & 0.39 & 0.97 \\
\hline 21 JUN 06 & 0.21 & 0.25 & 0.10 & 0.86 & 1.38 \\
\hline 22 JUN 06 & 0.10 & 0.21 & 0.05 & 0.25 & 1.42 \\
\hline 23 JUN 06 & 0.25 & 0.19 & 0.05 & 0.39 & 0.0 \\
\hline 24 JUN 06 & 0.18 & 0.04 & 0.22 & 0.32 & 0.41 \\
\hline 25 JUN 06 & 0.19 & 0.13 & 0.25 & 0.40 & \multirow{2}{*}{0} \\
\hline
\end{tabular}


Hussein et al. [8] presented a "U-shape" relationship between the wind speed and particles larger than $100 \mathrm{~nm}$ (minimum in the particle concentration occurred with wind speed of around $5 \mathrm{~m} . \mathrm{s}^{-1}$, higher wind speed enhanced resuspension) whereas for the ultrafine particles $(<100 \mathrm{~nm})$, the effect of dilution was clear, and the wind speed seldom exceeded $5 \mathrm{~m} \cdot \mathrm{s}^{-1}$.

Correlation matrices for daytime and night-time wind speed and concentrations are shown below.

Correlation matrix between day-time wind speed and concentrations

$\begin{array}{llllll} & \text { WS } & \text { PM10 } & \text { PM2.5 } & \text { PM1 } & \text { PM }<1 \\ \text { WS } & 1.0000 & 0.5308 & 0.4096 & 0.1022 & -0.1214 \\ \text { PM10 } & 0.5308 & 1.0000 & 0.7968 & 0.6048 & 0.7337 \\ \text { PM2.5 } & 0.4096 & 0.7968 & 1.0000 & 0.2485 & 0.5264 \\ \text { PM1 } & 0.1022 & 0.6048 & 0.2485 & 1.0000 & 0.4677 \\ \text { PM<1 } & -0.1214 & 0.7337 & 0.5264 & 0.4677 & 1.0000\end{array}$

Correlation between night-time wind speed and concentrations

$\begin{array}{llrrrr} & \text { WS } & \text { PM10 } & \text { PM2.5 } & \text { PM1 } & \text { PM }<1 \\ \text { WS } & 1.0000 & -0.1396 & 0.8254 & -0.8308 & 0.0572 \\ \text { PM10 } & -0.1396 & 1.0000 & -0.1701 & -0.1791 & 0.4134 \\ \text { PM2.5 } & 0.8254 & -0.1701 & 1.0000 & -0.5781 & 0.4811 \\ \text { PM1.0 } & -0.8308 & -0.1791 & -0.5781 & 1.0000 & -0.1279 \\ \text { PM<1 } & 0.0572 & 0.4134 & 0.4811 & -0.1279 & 1.0000\end{array}$

A positive correlation between with $\mathrm{R}=0.53$ for $\mathrm{PM} 10$ and $\mathrm{R}=0.41$ for PM2.5 was observed during day-time. A positive correlation with $\mathrm{R}=0.83$ for $\mathrm{PM} 2.5$ and a negative correlation with $\mathrm{R}=-0.83$ for $\mathrm{PM} 1$ was observed for night-time sampling periods. There are no significant correlations between wind speed and smaller particles (PM1 and $\mathrm{PM}<1)$.

\subsection{Inhalability, deposition and wind speed}

Table 3 shows an increase in IF and DF for each size of PM at wind speeds greater than $4 \mathrm{~m} . \mathrm{s}^{-1}$ was investigated. A correlation matrix for inhalable fraction, deposition and wind speed for PM10 and PM2.5 was obtained to ascertain the relationships.

The correlation matrix obtained showed high positive correlations with $\mathrm{R}=$ 0.99 for wind speed and inhalable fraction, and wind speed and deposition fraction.

$\begin{array}{lccc} & \text { WS } & \text { IF } & \text { DF } \\ \text { WS } & 1.0000 & 0.9992 & 0.9992 \\ \text { IF } & 0.9992 & 1.0000 & 1.0000 \\ \text { DF } & 0.9992 & 1.0000 & 1.0000\end{array}$

The matrix also shows a perfect positive correlation of $\mathrm{R}=1.00$ between the inhalable fraction and deposition fraction. 
Table 3: $\quad$ Inhalability, respiratory deposition and wind speed.

\begin{tabular}{|c|c|c|c|c|}
\hline \multirow{2}{*}{ Wind Speed $\left(\mathrm{m} \cdot \mathrm{s}^{-1}\right)$} & \multicolumn{2}{|c|}{$10 \mu \mathrm{m}$} & \multicolumn{2}{|c|}{$2.5 \mu \mathrm{m}$} \\
\hline & IF & $\overline{D F}$ & IF & $\overline{\mathrm{DF}}$ \\
\hline 4.1 & 1.00048400 & 1.91362171 & 1.00048423 & 1.913625662 \\
\hline 4.2 & 1.00051720 & 1.91368521 & 1.00051743 & 1.913689163 \\
\hline 4.3 & 1.00055180 & 1.91375139 & 1.00055203 & 1.913755343 \\
\hline 4.4 & 1.00058790 & 1.91382044 & 1.00058813 & 1.913824391 \\
\hline 4.5 & 1.00062540 & 1.91389216 & 1.00062563 & 1.913896117 \\
\hline 4.6 & 1.00066430 & 1.91396657 & 1.00066453 & 1.913970522 \\
\hline 4.7 & 1.00070480 & 1.91404403 & 1.00070503 & 1.914047986 \\
\hline 4.8 & 1.00074690 & 1.91412456 & 1.00074713 & 1.914128511 \\
\hline \multirow{2}{*}{ Wind Speed $\left(\mathrm{m} \cdot \mathrm{s}^{-1}\right)$} & \multicolumn{2}{|c|}{$1.0 \mu \mathrm{m}$} & \multicolumn{2}{|c|}{$0.4 \mu \mathrm{m}$} \\
\hline & IF & $\overline{D F}$ & IF & DF \\
\hline 4.1 & 1.00048427 & 1.91362613 & 1.00048429 & 1.913626264 \\
\hline 4.2 & 1.00051747 & 1.91368963 & 1.00051749 & 1.913689765 \\
\hline 4.3 & 1.00055207 & 1.91375581 & 1.00055209 & 1.913755945 \\
\hline 4.4 & 1.00058817 & 1.91382486 & 1.00058819 & 1.913824993 \\
\hline 4.5 & 1.00062567 & 1.91389659 & 1.00062569 & 1.913896720 \\
\hline 4.6 & 1.00066457 & 1.91397099 & 1.00066459 & 1.913971124 \\
\hline 4.7 & 1.00070507 & 1.91404846 & 1.00070509 & 1.914048588 \\
\hline 4.8 & 1.00074717 & 1.91412898 & 1.00074719 & 1.914129113 \\
\hline
\end{tabular}

\section{Conclusion}

The study has shown that inhalability and deposition increase with decrease in particle size, which emphasises the health effects of small particles.

The effect of high wind speeds was also shown to increase the inhalability and deposition of particles, which put children and the youth at higher risk because of their activities that normally lead to high respiratory rates.

Correlation between PM and wind speed is not always obvious, and may differ according to particle size and wind speed.

For wind speeds greater than $4 \mathrm{~m} \cdot \mathrm{s}^{-1}$, respiratory deposition increases as inhalability increases.

\section{Acknowledgements}

The authors acknowledge the role played by Ms Amanda Bubu of the Department of Physics, North-West University in collection of PM samples using the cascade impactors. The financial support of the Finnish Environment 
Institute (SYKE), the National Research Foundation (NRF), and North-West University is greatly acknowledged.

\section{References}

[1] Hinds, WC. Aerosol Technology: Properties, behavior, and measurement of airborne particles. 2nd edition. New York: John Wiley \& Sons. 1999.

[2] Vincent, J.H. Aerosol Sampling: Science and Practice. Chichester: Wiley. P. 416. 1989.

[3] Dabberdt, W.F., Frederick, G.L., Hardesty, R.M., Lee, W.C. \& Underwood, $\mathrm{K}$. Advances in meteorological instrumentation for air quality and emergency response. Meteorology and Atmospheric Physics, 87: 57-88. 2004.

[4] Preston-Whyte RA, \& Tyson PD, The atmosphere and weather of Southern Africa, New York: Oxford University Press. 366p. 1988.

[5] Vincent, J.H., Mark, D., Miller, B.H., Armbruster, L. \& Ogden, J.L. Aerosol inhalability at high speeds. Journal of Aerosol Science. 21: 577-586. 1990.

[6] Hinds, W.C., Kennedy, N.J. \& Tatyan, K. Inhalability of large particles for mouth and nose breathing. Journal of Aerosol Science, 29: S277-S278. 1998.

[7] Chow, J.C., Watson, J.G., Ashbaughb, L.L. \& Magliano, K.L. Similarities and differences in PM10 chemical source profiles for geological dust from the San Joaquin Valley, California. Atmospheric Environment, 37: 13171340. 2003.

[8] Hussein, T., Hämeri, K., Aalto, P.P., Paatero, P. \& Kulmala, M. Modal structure and spatial-temporal variations of urban and suburban aerosols in Helsinki-Finland. Atmospheric Environment, 39: 1655-1668. 2005. 